\title{
REDES DE PEQUENAS EMPRESAS: A APLICAÇÃO DE UMA TI POLOGIA EM UMA REDE DE SUPERMERCADOS
}

\section{NETWORKS OF SMALL FIRMS: A TIPOLOGY TRIAL IN A SUPERMARKETS NETWORK}

\section{ISRAEL FERREIRA JÚNIOR}

Mestrando em Administração pelo Centro de Pesquisa e Pós-Graduação em Administração da Universidade Federal do Paraná (Ceppad/UFPR) e bacharel em Administração pela Universidade Estadual Paulista (Unesp).

Rua Engenheiro Ostoja Roguski, 631, bloco 3, ap. 21, Jardim Botânico - Curitiba - PR - CEP 80210-390

E-mail: isjunior99@yahoo.com.br

\section{RIVANDA MEIRA TEIXEIRA}

Pós-doutorado em Gerenciamento de Pequenas Empresas do Setor Turístico (Strathclyde University - Escócia) e em Empreendedorismo em Turismo na École des Hautes Études Commerciales (HEC - Canadá).

Doutora em Administração pela Cranfield University (Inglaterra) e mestre em Administração pela Coppead (UFRJ).

Rua General Carneiro 885, ap. 701 Alto da Glória - Curitiba - PR - CEP 80060-150 E-mail: rivandateixeira@terra.com.br 


\section{RESUMO}

O presente estudo teve como objetivo analisar as características de uma rede do setor de comércio varejista,a Rede Econômica de Supermercados,de acordo com a ti pologia de redes de empresas proposta por Hoffmann etal. (2004). Além disso, buscou-se identificar quais são os princi pais benefícios e dificuldades verificados na operacionalização da Rede. A partir de entrevistas realizadas com o gestor administrativo da Rede e com um gerente de compras,e com base na análise de documentos e material institucional,pode-se classificar a Rede como de cooperação horizontal,aglomerada,formal e não-orbital. As princi pais vantagens percebidas para os supermercados,com relação à partici pação na rede,foram a realização de ações de marketing e de compras conjuntas. A princi pal dificuldade apontada reside na conciliação dos objetivos do negócio com os objetivos individuais.

\section{PALAVRAS-CHAVE}

Redesde empresas; Redesde cooperação; Aliançasestratégicas; Ti pologia de redes; Pequenas empresas; Supermercados.

\section{ABSTRACT}

The presentstudy intended to analyze the characteristics in a retail supermarket network, the "Rede Econômica de Supermercados",according to the typology of networks made by Hoffmann etal. (2004). Besides, itwas soughtto identify which are the main benefits and difficulties for operating a network. Through interviews made with the network manager,the supply manager and also through the analysis of the companies' documents and reports,itwas possible to classify the network as "horizontal","clustered", "formal" and "non-orbital". The main benefits perceived for the supermarkets in relation to their participation in the network were: joint marketing and purchasing. The main difficulty found was balancing business goals with individual goals. 


\section{KEYWORDS}

Business networking; Networks cooperation; Strategic alliances; Typology of networks; Small business; Supermarkets.

\section{INTRODUÇ ÃO}

A competição global pelos mesmos mercados e o conseqüente aumento na intensidade da concorrência têm gerado grandes pressões externas para as empresas. Estas,para se manterem competitivas,devem passar por processos de reestruturação,a fim de atenderem a determinados níveis de qualidade e custo que,muitas vezes,são viáveis apenas no universo das grandes empresas. Assim, os maiores prejudicados por alterações no ambiente competitivo têm sido as pequenas e médias empresas (CARRÃO,2004; FARIAS FILHO etal.,I999). Esse novo contexto competitivo tem exigido das empresas uma resposta que, na maioria das vezes,está ligada à constituição de novas formas de relação intra e interempresas, particularmente aquelas envolvendo as pequenas e médias (AMATO NETO,2000).

Em virtude da maior complexidade das funções desempenhadas pelas empresas,que são imprescindíveis para a sobrevivência no mercado,verifica-se cada vez mais a necessidade do trabalho realizado de forma associada ou cooperativada com outras empresas. Isso tem contribuído para a diminuição dos riscos e o aumento de sinergia entre as empresas,especialmente no que diz respeito às pequenas empresas (CASSAROTO FILHO; PIRES,I998). O acesso a informações,tecnologia,mercado consumidor e fornecedor,tão disputados atualmente, é uma barreira que as pequenas empresas dificilmente conseguem superar sozinhas (CARRÃO, 2004).

De maneira geral,pode-se dizer que foi a partir dos anos i970 que a cooperação entre empresas passou a ganhar notoriedade,em virtude de mudanças ocorridas nas formas de organização industrial. Essas mudanças tiveram como propulsores a criação dos distritos industriais, formados a partir de redes de pequenas empresas,na chamada Terceira Itália. Além disso,houve a influência das redes de empresas no Japão,na Coréia e em Taiwan,do chamado Vale do Silício nos Estados Unidos e dos sistemas produtivos locais na França,na Alemanha e no Reino Unido (CARRÃO,2004; AMATO NETO,2000).

Desse modo,em face das pressões ambientais,percebe-se que a cooperação é uma solução que tem sido adotada,por meio do estabelecimento das redes de empresas,especialmente pelas pequenas e médias,como forma de sobrevivência ou como mecanismo para o aumento da competitividade,principalmente em 
relação às grandes empresas. Diante do exposto,faz-se necessária uma maior compreensão das redes interorganizacionais que têm possibilitado a cooperação entre as empresas.

O objetivo deste artigo é analisar uma rede de pequenas empresas no setor de comércio varejista,a Rede Econômica de Supermercados. O estudo tem como base a análise das características da Rede de acordo com a tipologia proposta por Hoffmann etal. (2004), a qual se baseia nos indicadores de direcionalidade,localização,formalização e poder. Além da classificação da Rede de acordo com a sua ti pologia,o trabalho tem como objetivo verificar quais os principais benefícios proporcionados pela associação dos supermercados em rede,a lém das princi pais dificuldades verificadas para o seu funcionamento.

O presente artigo,após a introdução,apresenta o referencial teórico,que trata dos tópicos de redes interorganizacionais, das princi pais ti pologias e das redes de pequenas e médias empresas (PME). A seguir,uma seção aponta o estado da arte de alguns trabalhos relevantes sobre o tema. Em seguida,são detalhados os aspectos metodológicos do estudo. Na seqüência,encontra-se a análise do caso e,por fim,têm-se as conclusões do trabalho.

\section{REFERENCIAL TEÓRICO}

\subsection{REDES INTERORGANIZACIONAIS}

Uma exata definição do que seja rede interorganizacional constitui tarefa difícil,já que o conceito de rede é muito abrangente e complexo. Para Carrão (2004), a multiplicidade de formatos existentes, dentro do campo da cooperação entre empresas,impede uma homogeneidade conceitual,razão pela qual se entende que a conceituação do que seja rede deve guiar-se por suas características básicas e mais comuns.

Conforme já foi apontado anteriormente,as empresas têm passado por novas necessidades e exigências,que seriam de difícil atendimento se as empresas atuassem de maneira isolada. Segundo Amato Neto (2000), a cooperação interempresarial pode viabilizar o atendimento de uma série de necessidades, entre as quais se destacam: combinar competências e utilizar o know-how de outras empresas; dividir ônus de realizar pesquisas tecnológicas,compartilhando o desenvolvimento e conhecimento adquirido; partilhar riscos e custos de explorar novas oportunidades, realizando experiências em conjunto; oferecer uma linha de produtos de qualidade superior e mais diversificada; exercer maior pressão sobre o mercado; compartilhar recursos; forta lecer o poder de compra; e ter força para atuar em mercados internacionais. 
Segundo Laniado e Baiardi (2003),a cooperação é percebida como conjunto de recursos estruturados por meio de redes. Hoffmann etal. (2004) indicam que as motivações para a formação de uma rede podem ser diversas,como estas: complexidade de produtos; troca de conhecimento; aprendizagem organizacional e disseminação da informação; demanda por rapidez de resposta; confiança e cooperação; e defesa contra a incerteza.

De maneira geral,as redes de empresas se baseiam em um formato organizacional que utiliza ti pos inovadores de alianças,que permitem combinar eficácia,informalidade e espontaneidade,rompendo assim com modelos ortodoxos de organização. Em virtude das muitas articulações e interações,os relacionamentos que ocorrem dentro de uma rede são,ao mesmo tempo,dinâmicos e complexos (CARRÃO,2004).

Uma rede de empresas é composta por um conjunto ou grupo de organizações interconectadas por relações bem definidas,as quais podem ser de um mesmo setor ou estar situadas ao longo de uma cadeia produtiva (BALESTRO etal.,2003). Pode-se compreender que uma rede interfirmas constitui-se no modo de regular a interdependência de sistemas complementares, tais como produção,pesquisa, engenharia e outros,em objetivos comuns. Dessa forma,as competências e atribuições de uma rede de empresas estão basicamente ligadas aos processos de coordenação que uma coalizão entre empresas pode empregar (AMATO NETO,2000).

Jarillo (I988) descreve as redes como acordos de longo prazo,com propósitos claros,entre empresas distintas mas relacionadas,que permitem que aquelas empresas estabeleçam ou sustentem uma vantagem competitiva,em face das empresas presentes fora da rede.

A vantagem competitiva propiciada pela ação em rede das empresas pode surgir de muitas fontes,entre as quais podem ser citadas as seguintes: o aprendizado mútuo entre as empresas, que leva a uma melhoria e maior rapidez no desenvolvimento de produtos; a estratégia de co-especialização,pela qual as empresas da rede encontram novos nichos lucrativos de mercado e de produtos; o melhor fluxo e coordenação das informações entre as empresas,o que leva a economias de custo e de tempo; as economias de escala,que podem ser alcançadas por meio de acordos para a realização de esforços conjuntos de pesquisa; e as barreiras de entrada,que são levantadas pela rede,como forma de defender a lucratividade das empresas (EBERS; JARILLO,I997).

Conforme Carrão (2004),em uma rede de cooperação entre empresas existe maior ênfase no enfoque coletivo em substituição ao individual. A complexidade de uma rede de empresas vem da necessidade de facilitar a comunicação entre os membros e da tentativa de tornar coerentes os objetivos da rede com os objetivos de seus componentes. Segundo Farias Filho etal. (I999),um dos objetivos comuns de uma rede de cooperação é a sobrevivência das empresas que compõem o grupo. 
O alcance de objetivos comuns a todos os membros do grupo é algo complexo,pois uma rede é construída com base em interações de indivíduos e organizações que,muitas vezes,possuem interesses conflitantes. Em virtude da variedade de interesses individuais dentro da rede,sua estrutura torna-se muito importante,pois são as estruturas de interação que possibilitam o alcance dos objetivos pessoais e coletivos,constituindo um equilíbrio entre autonomia e dependência (BALESTRO,2004).

De acordo com Amato Neto (2000),três variáveis são determinantes na formação das redes de empresas: a diferenciação,a interdependência interfirmas e a flexibilidade. A diferenciação,quando relacionada a uma rede,pode prover seus benefícios inovadores a todos os seus partici pantes. Já a interdependência de firmas se traduz por um mecanismo que efetivamente prediz a formação de redes e que,por isso,é adotado como unidade organizacional. A flexibilidade,tanto no aspecto inovador e produtivo como no próprio aspecto organizacional,é uma das maiores propriedades das redes,já que algumas podem arranjar-se de conformidade com suas contingências e necessidades.

De acordo com Doz (1996), o caminho da evolução das relações de cooperação em uma rede pode apresentar quatro estágios. No estágio inicial,são definidas as condições iniciais da cooperação, tais como definição de tarefas, rotinas organizacionais dos membros e estrutura de interação das empresas com as expectativas dos parceiros em relação ao desempenho da cooperação. No segundo estágio,essas condições poderão ou não conduzir a uma aprendizagem em relação ao ambiente competitivo,às tarefas da cooperação,ao processo, às habilidades a serem desenvolvidas e às metas a serem atingidas. No estágio seguinte,a aprendizagem permite uma reavaliação da cooperação quanto a sua eficiência,adaptabilidade e retorno financeiro. E por fim,no quarto e último estágio,a reavaliação conduz a uma revisão das condições iniciais estabelecidas no primeiro estágio.

O processo de desenvolvimento de relações interorganizacionais,para Ring e Van de Ven (I994,apud BALESTRO,2004),possui três etapas: os estágios das negociações, do comprometimento e de execução das relações de cooperação. No estágio das negociações, as partes desenvolvem expectativas conjuntas em torno de duas motivações, de possíveis investimentos e de incertezas percebidas no empreendimento que ambos vão explorar conjuntamente. No estágio do comprometimento, as partes chegam a um acordo quanto às obrigações e às regras para ação futura no relacionamento entre as empresas. Nesse momento, as características e a estrutura de governança da relação são estabelecidas. Por fim,há o estágio das execuções,em que os comprometimentos e os regramentos são executados. Durante o estágio das execuções,as interações permitem o surgimento de relações interpessoais que,por sua vez,contribuem para as relações interorganizacionais. 


\subsection{TIPOLOGIA DE REDES}

Alguns fatores são utilizados para classificar e diferenciar os tipos de redes. Os mais utilizados são estes: dependência estratégica das partes; formação relacional; flexibilidade da produção; integração da produção; grau de compartilhamento das funções; objetivos e amplitude deles; tempo de duração; setores industriais envolvidos; grau e ti po de ligação e vínculos entre as partes; liderança de organizações centrais; entre outros (FARIAS FILHO etal.,I999).

Quando se trata de ti pologia de redes de empresas,uma das mais conhecidas e citadas na literatura é a classificação proposta por Grandori e Soda (I995), a qual é elaborada de acordo com os seguintes critérios: tipo de mecanismo de coordenação utilizado,grau de centra lização e grau de formalização da rede. Para esses autores,são três os ti pos básicos de rede,explicitados em seguida.

- As redes sociais (social networks) têm por característica fundamental a informalidade nas relações interempresariais,isto é,prescindem de qualquer tipo de acordo ou contrato formal. São subdivididas entre redes sociais simétricas e assimétricas. As redes sociais simétricas caracterizam-se pela inexistência de poder centralizado,ou seja,todos os partici pantes dessa rede compartilham a mesma capacidade de influência. Já nas redes assimétricas,há a presença de um agente central que tem por função primordial coordenar os contratos formais de fornecimento de produtos e/ou serviços entre as empresas e organizações que partici pam dessa rede.

- As redes burocráticas são caracterizadas pela existência de contrato formal, que se destina a regular não somente as especificações de fornecimento de produtos e serviços,como também a própria organização da rede e as condições de relacionamento entre seus membros. Também são subdivididas em simétricas e assimétricas.

- As redes proprietárias caracterizam-se pela formalização de acordos relativos ao direito de propriedade entre acionistas de empresas. Podem ser também simétricas ou assimétricas.

Em seu trabalho,Hoffmann etal. (2004) propõem uma ti pologia de redes de empresas com base em ampla pesquisa bibliográfica do tema. Com base em quatro indicadores (direcionalidade,localização,formalização e poder), os autores apresentam uma ti pologia,cujas princi pais características estão resumidas na Tabela I e serão detalhadas a seguir,com a indicação de outros autores. 


\section{TABELA I}

TIPOLOGIA DE REDES DE EMPRESAS

\begin{tabular}{ll}
\hline INDICADORES & TIPOLOGIA \\
\hline Direcionalidade & $\begin{array}{l}\text { Vertical } \\
\text { Horizontal }\end{array}$ \\
\hline \multirow{2}{*}{ Localização } & Dispersa \\
& Aglomerada \\
\hline \multirow{2}{*}{ Formalização } & Base contratual formal \\
& Base não-contratual formal \\
\hline \multirow{2}{*}{ Poder } & Orbital \\
& Não-orbital \\
\hline
\end{tabular}

Fonte: Hoffmann etal. (2004).

No que se refere à direcionalidade, as relações em uma rede podem ocorrer tanto no sentido vertical quanto no horizontal (FARIAS FILHO etal.,I999; AMATO NETO,2000; CARRÃO,2004). Em uma rede vertical de cooperação, as relações ocorrem entre uma empresa e os componentes dos diferentes elos, ao longo de uma cadeia produtiva. Também são conhecidas como redes topdown, que é uma estrutura em que uma empresa de menor porte atua como fornecedora direta ou indireta para uma empresa-mãe,ou seja,nelas são estabelecidas ações típicas de compra e venda de produtos e/ou serviços,destinados ao fornecimento da contratante,razão pela qual são conhecidas como rede de fornecedores (por exemplo,indústria de automóvel).

As redes horizontais de cooperação são aquelas em que as relações de cooperação se dão entre empresas que produzem e oferecem produtos similares, pertencentes a um mesmo setor ou ramo de atuação,isto é,entre uma empresa e seus próprios concorrentes. Essas redes são mais especificamente definidas como relações típicas de cooperação entre empresas de pequeno porte,embora possam,igualmente,ocorrer entre empresas de grande porte. Em uma rede desse ti po,os objetivos devem estar sempre dirigidos aos ganhos que se podem obter pela união entre as partes.

Alguns autores (CASSAROTO FILHO; PIRES,I998; FARIAS FILHO etal., I999) vêem as redes horizontais de cooperação como redes flexíveis de produção,em que as empresas participantes se reúnem em um consórcio na busca de seus objetivos. Os três princi pais grupos de consórcio,de acordo com Cassaroto Filho e Pires (I998),são estes: consórcio setorial,consórcio territorial e consórcio específico. 
De acordo com Hoffmann etal. (2004), no que se refere à localização, as redes podem ser dispersas ou aglomeradas. As redes dispersas são aquelas que fazem uso de processo avançado de logística,como forma de superar distâncias para o a lcance da interação das partes. As redes aglomeradas territorialmente têm como característica a manutenção de relações que,muitas vezes, se estendem a lém daquelas puramente comerciais. Nesse tipo de rede,é possível encontrar igualmente instituições de suporte empresarial,como universidades,centros de tecnologia e instituições governamentais.

No que se refere ao aspecto da formalização,as redes podem ser estruturas formalizadas,por meio de base contratual,ou então ser informais,sem base contratual (HOFFMANN eta1.,2004; LANIADO; BAIARDI,2003). A escolha entre essas duas formas varia de acordo com os objetivos da rede. Em rede formal,o estabelecimento de vínculo contratual tem como objetivo garantir o cumprimento das regras estabelecidas e evitar comportamentos inadequados,que prejudiquem as relações entre os membros. Já na informal,as relações são estabelecidas na base da confiança,quando ocorre uma mistura das relações econômicas com as relações sociais.

Por fim,quanto ao poder de decisão, as redes podem ser orbitais ou não-orbitais (HOFFMANN etal.,2004). As redes orbitais se caracterizam por possuir hierarquia de poder,como no caso das redes formadas entre uma empresa e seus fornecedores. A rede não-orbital é uma rede onde todos os participantes têm a mesma capacidade de decisão.

\subsection{REDES DE PEQUENAS E MÉDIAS EMPRESAS}

Como já foi ressaltado anteriormente,o aumento da concorrência nos mercados,em virtude de mudanças no ambiente competitivo,afeta a sobrevivência das empresas,em especial as de pequeno e médio portes. Na maioria das vezes, as PME têm apresentado certas dificuldades que,de acordo com Balestrin e Vargas (2003),podem ser: obstáculos na obtenção de melhores preços e vantagens na compra de matérias-primas e componentes, custos de partici pação em feiras, custos de campanhas publicitárias,custos de reciclagem e treinamento da mãode-obra,atualização tecnológica,acesso a linhas de crédito e financiamento,custos de aluguel,custos envolvidos na exportação de produtos etc. Em decorrência desse contexto,a solução para as pequenas e médias empresas tem sido a cooperação,por meio do estabelecimento das redes (CARRÃO,2004; CASSAROTO FILHO; PIRES,I998).

Para Cassaroto Filho e Pires (I998),o grande problema da pequena empresa é a falta de competência para dominar todas as etapas da cadeia de valor,além 
da própria capacidade de gestão de todas as etapas. Também é muito improvável que,economicamente,uma pequena empresa possa dominar todas as funções da cadeia produtiva. Tal situação acaba prejudicando a competitividade da pequena empresa dentro de um setor. Nessas circunstâncias,a partir da formação de uma rede,as pequenas empresas têm a possibilidade de compartilhar e cooperar na execução das atividades iniciais e finais da cadeia de valor.

As etapas iniciais da cadeia de valor podem ser representadas por duas funções vitais: desenvolvimento de novos produtos e aquisição de matérias-primas. As funções finais da cadeia de valor se referem ao marketing e à logística de distribuição,já que estas são funções complexas que normalmente não podem ser desempenhadas por pequenas empresas que atuam isoladamente. Tanto as atividades iniciais quanto as finais da cadeia seriam mais bem desenvolvidas de forma cooperada por empresas de pequeno e médio portes (CASSAROTO FILHO; PIRES,I998).

Para Tondolo e Schneider (2004), o poder de investimento em propaganda, a abertura e o melhor controle dos canais de distribuição,a busca da garantia de um suprimento melhor, a redução dos custos na compra de produtos para venda e logística são algumas vantagens do estabelecimento de alianças entre as empresas. Para Pereira (2004), no que se refere à função de marketing,alguns benefícios que podem ser obtidos pela cooperação entre empresas são: compartilhamento da marca,melhoria da comunicação e da imagem das empresas no mercado e expansão do mix de produtos,a partir do relacionamento com fornecedores.

A produção é vista como etapa intermediária,que também pode ser realizada de forma compartilhada pelas empresas. Nesse compartilhamento,ocorre o uso conjunto de know-how e a divisão de riscos no desenvolvimento de novos processos (CASSAROTO FILHO; PIRES,I998).

As redes também possibilitam que as PME,por meio da estrutura da rede, se coloquem estrategicamente no mercado,fazendo uso de umas das estratégicas genéricas de Porter: liderança de custo,diferenciação de produto ou enfoque (TONDOLO; SCHNEIDER,2004). De modo geral,o objetivo da estratégia em rede é possibilitar que as pequenas empresas obtenham melhores condições de competição com as grandes empresas e atinjam os objetivos que dificilmente seriam alcançados individualmente. Os princi pais atributos estratégicos e seus objetivos correspondentes, de acordo com Balestrin e Vargas (2004), estão sintetizados na Tabela 2. 
TABELA 2

PRINCIPAIS ATRIBUTOS ESTRATÉGICOS

DAS REDES DE PME E SEUS OBJETIVOS

\begin{tabular}{ll}
\hline ATRIBUTOS & OBJETIVOS \\
\hline Fluidez & $\begin{array}{l}\text { Possibilitar maior flexibilidade e adaptabilidade aos fatores } \\
\text { externos. }\end{array}$ \\
\hline Agilidade & Evitar a dispersão de esforços e permitir um ganho de agilidade. \\
\hline Aprendizagem coletiva & Facilitar a aprendizagem coletiva pela interconexão entre os atores. \\
\hline Economias de escala & $\begin{array}{l}\text { Possibilitar economias de escala por meio da ação conjunta das } \\
\text { PME. }\end{array}$ \\
\hline $\begin{array}{l}\text { Acesso a recursos } \\
\text { tangíveis }\end{array}$ & $\begin{array}{l}\text { Possibilitar acesso a recursos tangíveis, como insumos, tecnologias } \\
\text { de processo, mão-de-obra etc. }\end{array}$ \\
\hline $\begin{array}{l}\text { Acesso a recursos } \\
\text { intangíveis }\end{array}$ & $\begin{array}{l}\text { Possibilitar o acesso a recursos intangíveis, como informações, } \\
\text { habilidades, competências etc. }\end{array}$ \\
\hline $\begin{array}{l}\text { Redução dos custos de } \\
\text { transação }\end{array}$ & $\begin{array}{l}\text { Reduzir os custos de transação pelo aumento de confiança entre } \\
\text { os atores, reduzindo as incertezas e o comportamento oportunista } \\
\text { entre as partes. }\end{array}$ \\
\hline $\begin{array}{l}\text { Credibilidade } \\
\text { organizacional }\end{array}$ & $\begin{array}{l}\text { Ganhar legitimidade externa pelo fato de a empresa estar } \\
\text { associada à determinada rede. }\end{array}$ \\
\hline
\end{tabular}

Para que as empresas possam estabelecer relações de cooperação dentro de uma rede,é essencial que exista confiança entre os membros. Segundo Perrow (I992,apud BALESTRIN; VARGAS,2003), existem algumas características no contexto das PME que possibilitam o desenvolvimento da confiança entre as firmas,como: a) as firmas compartilham e discutem informação sobre mercados, tecnologias e lucratividade; b) existe suficiente similaridade entre processo e técnicas das firmas,possibilitando maior compreensão do seu comportamento; c) as relações são estabelecidas em longo prazo; d) existe pouca diferença entre tamanho,poder ou posição estratégica das firmas; e) ocorre periódica rotação de lideranças para representar o conjunto de firmas; f) ocorre similar recompensa financeira para as firmas e empregados dentro delas; e g) alcance de vantagem econômica pela experiência coletiva das firmas,pelo aumento das vendas e pelos ganhos marginais. 
De acordo com Balestrin e Vargas (2004), uma rede horizontal de PME apresenta as seguintes características: a) é formada por um grupo de PME; b) as PME situam-se geograficamente próximas; c) as PME operam em segmento específico de mercado; d) as relações entre as PME são horizontais e cooperativas,prevalecendo mútua confiança; e) a rede é formada por indeterminado período de tempo; e g) a coordenação da rede é exercida com base em mínimos instrumentos contratuais que garantam regras básicas de governança.

Em rede horizontal de PME,existe uma multiplicidade de interesses dos membros que muitas vezes podem ser conflitantes. Nessas circunstâncias, o estabelecimento de mecanismos de governança é fundamental para o sucesso da rede. Para Balestro (2004), uma das questões mais importantes relativa à governança diz respeito à existência,ou não,de uma central de coordenação da rede,ou seja,existência de uma entidade composta por profissionais de fora das empresas ou por representantes delas,com a finalidade de monitorar as relações entre as empresas e gerenciar o processo de tomada de decisão coletiva.

Ainda segundo Balestro (2004),com base no trabalho de Grandori e Soda (I995), os mecanismos de governança mais presentes nas organizações em rede são estes: mecanismos de comunicação,decisão e negociação; controle e coordenação social; equi pe comum; relações de hierarquia e autoridade; sistemas de planejamento e controle; sistemas de incentivos; sistemas de seleção; sistemas de informação; e apoio público e infra-estrutura.

O funcionamento dos mecanismos de governança e a estabilidade das relações estão relacionados com a intensidade das normas e da confiança nas relações entre as empresas. Balestrin e Vargas (2004) lembram ainda que a dimensão da confiança e da cooperação representa papel fundamental no sucesso das redes de PME,que dificilmente será alcançado por outras formas de redes entre grandes empresas,e muito menos pelas grandes empresas integradas.

\subsection{ESTUDOS REALIZADOS EM REDES DE PME}

Recentemente,o tema de redes de PME tem sido abordado por considerável número de trabalhos,tanto nacionais quanto internacionais,que tem procurado abordar diferentes aspectos desse tema amplo e complexo.

O trabalho rea lizado por Wittmann etal. (2003) procurou identificar quais os benefícios proporcionados pela rede de cooperação,e de que maneira estes contribuíram para o aumento da competitividade em uma rede de micro e pequenos supermercados no Estado do Rio Grande do Sul. Os resultados mostraram que os princi pais benefícios obtidos por meio da rede foram as ações de marketing e o aumento do poder de negociação; o princi pal fator que dificulta a permanência na rede é o descumprimento de acordos e características culturais individualistas. 
Assim como o trabalho anterior,Tondolo e Schneider (2004) também buscaram identificar as vantagens que os pequenos varejistas do ramo farmacêutico obtêm no mercado por estarem associados a uma rede. O estudo de caso foi feito em uma rede gaúcha de pequenas farmácias. As vantagens identificadas foram as seguintes: I. sistema de suprimento,que envolve o compartilhamento de atividades de compras e distribuição de bens; 2 . atividades de apoio vinculadas à gestão de pessoas; 3. compartilhamento de atividades burocráticas; e 4. produtos com marca própria.

Hoffmann etal. (2004) tiveram como objetivo princi pal a elaboração de uma ti pologia para a classificação das redes de empresas,com base em revisão bibliográfica sobre o tema. Além disso,o trabalho buscou aplicar essa mesma ti pologia em algumas redes de empresas como forma de validá-la. Por meio de questionários e entrevistas,três redes do setor de cerâmica foram analisadas: duas no Brasil e uma na Espanha. Os resultados,a partir da aplicação da ti pologia,mostraram diferenças entre as redes pesquisadas, tanto entre os dois países como entre as duas redes nacionais.

A pesquisa realizada na região central do País de Gales,realizada por FullerLove e Thomas (2004), buscou investigar se as redes de empresas contribuem para o sucesso das pequenas empresas,a lém de descobrir as princi pais vantagens delas para as organizações partici pantes. Os resultados da pesquisa apontaram que as redes constituem um meio efetivo de melhorar o desempenho,por meio da redução de custos. Elas também provêem uma fonte valiosa de informação e de compartilhamento de recursos. Algumas vantagens percebidas por pertencer a uma rede são: contatos pessoais,informação,idéias, solução de problemas e melhoria da eficiência.

Com base em metodologia não muito costumeira nos trabalhos sobre redes, Carstens e Teixeira (2005) buscaram realizar um debate sobre a cooperação entre pequenas empresas em rede interorganizacional,como fator de vantagem competitiva e de aprendizado para as organizações integrantes,por meio de revisão bibliográfica e da elaboração de um "estado da arte",ou seja,as autoras realizaram amplo levantamento dos estudos de redes de PME. As princi pais vantagens identificadas nos estudos foram as seguintes: trocas de informações e conhecimentos,aumentando a aprendizagem, lobbying e maior poder de negociação com fornecedores, maior facilidade de comercialização em novos mercados, melhorias nos processos empresariais,redução de despesas de marketing e atendimento de uma série de outras necessidades das empresas.

Com foco mais especifico,o trabalho de Pereira (2004) procura analisar a função de marketing dentro de uma rede de cooperação,formada por varejistas de materiais de construção. Os resultados do trabalho apontam que,do ponto de vista dos parceiros,o estabelecimento da rede tem notável importância tanto no 
marketing quanto na aprendizagem organizacional. Ações de marketing,que não poderiam ser realizadas individualmente por causa dos altos custos,são possibilitadas pela divisão dos custos entre os membros da rede. Outro ponto positivo verificado se refere à padronização do nível de serviços em todas as lojas da rede, o que aumentou a qualidade do atendimento dos clientes.

Em sua dissertação de mestrado, Wilder (2003) realizou uma pesquisa na área de cooperação entre pequenas empresas. O trabalho teve como objetivo analisar a formação de associação de compras por pequenos supermercados. O estudo foi realizado em duas redes de cidades diferentes (Limeira e Piracicaba),sendo uma delas,coincidentemente,a rede-foco do presente estudo. Em primeiro lugar, por tratar-se de trabalho mais amplo e completo,o autor estudou o setor supermercadista,utilizando a Teoria da Organização Industrial. Dessa maneira,foram verificadas as seguintes características do setor: possui baixas barreiras à entrada; a entrada pode ocorrer de forma "tempestiva",ou seja,em menos de dois anos; existem consideráveis economias de escala; o princi pal fator na escolha do consumidor é o preço médio de uma cesta de produtos; e possui um número grande de empresas atuando,porém a rede bruta se concentra em grandes empresas.

As duas associações escolhidas por Wilder (2003) foram estudadas sob duas ópticas: a economia dos custos de transação e a de ação coletiva,visando saber "como" e "por que" a formação de associação de redes independentes é uma estratégia para melhorar a competitividade dos pequenos supermercados. Entre os benefícios observados, destacam-se algumas vantagens típicas de grandes empresas,como aumento do poder de negociação e redução dos custos de propaganda,a lém da possibilidade de melhorar a administração das lojas. As dificuldades se referem,princi palmente, às discordâncias dentro do grupo e aos problemas tributários que inviabilizaram as compras conjuntas nas redes estudadas.

\section{ASPECTOS METODOLÓGICOS}

Este estudo de abordagem qualitativa se configura como pesquisa descritiva, visto que ela expõe características de um determinado fenômeno (VERGARA, I998). O método utilizado foi o estudo de caso,que possibilita investigação mais profunda e exaustiva de um fenômeno atual,dentro de seu contexto de realidade (GIL,I999; YIN,200I). Esse estudo de caso foi realizado na Rede Econômica de Supermercados, tendo a sede em Limeira,SP. A escolha desse caso se deu em decorrência de a Rede Econômica destacar-se no setor de supermercados,tanto no âmbito local quanto regional,e por propiciar aos seus associados a possibilidade de sobreviver e competir em ambiente de disputa cada vez mais acirrada, em virtude da presença de grandes concorrentes. 
Inicialmente,rea lizou-se uma pesquisa bibliográfica em livros e artigos científicos que tratavam do tema de redes de PME. Essa etapa teve como principal objetivo situar o pesquisador com relação aos diversos aspectos já investigados dentro desse tema,além de fornecer base teórica para o estudo. Como o estudo de caso exige o uso de múlti plas fontes de evidência (YIN,200I),realizou-se também a análise de documentos e material institucional da rede,que foram fundamentais para a descrição das características do setor e para maior compreensão da rede em estudo e das empresas partici pantes.

A coleta de dados se deu por meio de entrevistas semi-estruturadas com o gestor administrativo da rede e com o gerente de compras. A técnica de entrevista pessoal foi utilizada em virtude de sua maior flexibilidade,o que permite a obtenção de respostas mais confiáveis,já que os significados das perguntas podem ser explicados pelo entrevistador em caso de dúvida (GIL,I999). Os entrevistados foram escolhidos por terem as informações que possibilitaram o alcance do objetivo da pesquisa,sem a necessidade de realização de entrevistas com os proprietários das lojas. As princi pais informações foram obtidas a partir da entrevista com o gestor administrativo; o gerente de compras prestou informações adicionais e complementares.

As questões da entrevista foram formuladas com base nos quatro indicadores da ti pologia apresentada por Hoffmann etal. (2004): direcionalidade, localização,formalização e poder,além de possuir questões ligadas às vantagens percebidas pelos associados, bem como as dificuldades inerentes ao processo de associação em rede. Após a coleta de dados,procedeu-se à análise de conteúdo de forma sistemática e objetiva,com o intuito de obter inferências confiáveis sobre o objeto de estudo,com base nos dados e nas informações levantados.

\section{ANÁLISE DO CASO}

O caso da Rede Econômica de Supermercados será apresentado em cinco etapas,que são: caracterização do setor de supermercados; descrição da Rede Econômica de Supermercados; aplicação da ti pologia,segundo os indicadores de direcionalidade,formalização,localização e poder; vantagens proporcionadas pela Rede; e as dificuldades percebidas no processo de associação em Rede.

\subsection{CARACTERIZAÇÃO DO SETOR DE SUPERMERCADOS}

Segundo o Sebrae (2005), os supermercados são considerados empresas do comércio varejista, pois vendem mercadorias diretamente ao consumidor. Por 
fazer parte do setor de comércio,um supermercado é considerado microempresa quando possui até nove empregados,e pequena empresa quando conta com Io a 49 pessoas ocupadas. De acordo com a Associação Brasileira de Supermercados (Abras), citada por Wilder (2003), as empresas do setor são classificadas pelo número de lojas. São chamadas redes ou cadeias as firmas que possuam seis ou mais lojas,e rede ou cadeias independentes as que contam com cinco ou menos lojas. Conforme a área de vendas,o número médio de itens disponíveis, a porcentagem de vendas de produtos não-alimentares e o número de caixas e de seções,as lojas podem ser classificadas em: a) loja de conveniência; b) loja de sortimento limitado; c) supermercado compacto; d) supermercado convencional; e) superloja; f) hi permercado; g) loja de depósito; e h) clube atacadista.

Atualmente,o mercado brasileiro de supermercados é formado por grande número de pequenas empresas,bem como por pequeno grupo de grandes redes que,a partir da década de I990,passaram a ampliar o seu mercado de atuação do nível regional para o nacional,princi palmente em virtude da entrada de empresas internacionais. Essas empresas têm procurado aumentar a sua partici pação no mercado por meio das mais diferentes estratégias,como aquisições e fusões (WILDER,2003).

Uma das estratégias que os supermercados de menor porte utilizam para competir com os grandes grupos é a de associação em redes,principalmente para a realização de compras. Contudo,segundo Wilder (2003), a formação de associações entre supermercados independentes não é recente. Desde a década de I920,existem,nos Estados Unidos,associações que têm o intuito de fortalecer os supermercadistas que estavam com dificuldades em competir com as grandes redes,pois estas últimas detinham maior poder de negociação com indústrias e fornecedores.

No Brasil,a associação mais antiga entre supermercados para a realização de compras foi fundada em I980,com o surgimento da Associação Varejista do Espírito Santo (Avaes). Atualmente,as dez maiores associações do país são constituídas, em média, por empresas com uma loja pequena,quatro caixas e um número reduzido de funcionários. A maioria das centrais de compras tem, atualmente,entre três e cinco anos e uma característica de crescimento lento, pois agregam aos poucos novos associados (WILDER,2003). As centrais de compras trazem vantagens tanto para os consumidores quanto para os supermercadistas,fornecedores e funcionários. As princi pais vantagens estão sintetizadas na Tabela 3. 
TABELA 3

PRINCIPAIS VANTAGENS DAS ASSOCIAÇÕES

DE COMPRAS ENTRE SUPERMERCADOS

\begin{tabular}{ll}
\hline GRUPOS & VANTAGENS \\
\hline Consumidores & Melhores preços, qualidade, promoções e melhor atendimento. \\
\hline Supermercadistas & $\begin{array}{l}\text { Perspectiva de melhora da loja e de crescimento, troca de experiências, } \\
\text { aumento nas vendas e ampliação do mix de produtos. }\end{array}$ \\
\hline Fornecedores & $\begin{array}{l}\text { Aumento no volume de vendas, redução de intermediários e redução } \\
\text { dos custos de marketing e transporte. }\end{array}$ \\
\hline Funcionários & Treinamentos técnicos e possibilidade de crescimento profissional. \\
\hline
\end{tabular}

Fonte: Wilder (2003).

A união entre supermercados para a constituição de associações de compras pode ser vista como um dos primeiros passos para a formação de uma estrutura em rede que possua outras funções a lém da rea lização de compras conjuntas.

\subsection{A REDE ECONÔMICA DE SUPERMERCADOS}

A Rede começou formalmente em meados de I998,com a partici pação de dez lojas associadas. Atualmente,a Rede conta com dezoito lojas,que pertencem a treze proprietários distintos,distribuídas nas cidades de Limeira (I6),Iracemápolis (I) e Santa Bárbara d'Oeste (I).

O surgimento da Rede Econômica se deu por iniciativa de seu atual presidente que,na época,possuía cinco lojas,e cuja princi pal motivação era aumentar o poder de negociação com os grandes fornecedores, ou seja,em seu início,a principal função da Rede seria a realização de compras conjuntas. Segundo o depoimento do gestor da Rede,

grandes empresas,como Unilever ou Nestlé,só vendem seus produtos a partir de uma determinada quantidade nos pedidos, o que muitas vezes inviabiliza a compra direta dos pequenos supermercados junto a essas empresas.

A fusão de grandes redes de supermercados e a vinda dos grandes hipermercados para a cidade de Limeira são fatores que,para o entrevistado,contribuíram para a formação da Associação Rede Econômica de Supermercados (nome jurídico). 
Com base nos critérios de área de vendas e número de caixas,definidos pela Associação Brasileira de Supermercados,as lojas pertencentes à Rede Econômica se enquadram na classificação apresentada na Tabela 4.

\section{TABELA 4}

\section{CLAS SIFICAÇÃO DOS ESTABELECIMENTOS SEGUNDO A ABRAS}

\begin{tabular}{llc}
\hline CLASSIFICAÇÃO & CRITÉRIOS & No DE LOJAS \\
\hline Loja de conveniência & Área de vendas 50-250 m²; n. de caixas 1-2. & 3 \\
\hline Loja de sortimento limitado & Área de vendas 200-400 m²; n. de caixas 2-4. & 10 \\
\hline Supermercado compacto & Área de vendas 300-700 $\mathrm{m}^{2}$; n. de caixas 2-6. & 5 \\
\hline
\end{tabular}

Fonte: Dados da pesquisa.

De acordo com os critérios de número de funcionários,definidos pelo Sebrae, as lojas da rede são dos seguintes ti pos: duas lojas classificadas como microempresa (com até nove pessoas empregadas) e dezesseis lojas enquadradas como pequena empresa (de io até 49 pessoas empregadas).

O processo de associação à Rede Econômica se dá por meio de convite. Em seu início,a busca feita pelo fundador por lojas que pudessem associar-se concentrou-se em dois critérios princi pais: localização geográfica e porte da empresa. A preocupação com a localização geográfica dos estabelecimentos tinha como principal objetivo evitar que estes estivessem muito próximos entre si,situação que fatalmente traria problemas para a relação de cooperação/competição entre os membros da Rede.

Com relação ao porte da empresa,a preocupação era no sentido de que não seria interessante para a Rede Econômica ter empresas com grandes diferenças de faturamento. Segundo o gestor,essa situação levaria a conflitos de interesses, na medida em que lojas maiores poderiam querer ter maior poder de influência dentro da associação. Além desses dois critérios já citados,também foi levada em conta,por ocasião da entrada dos participantes na rede,a situação financeira das lojas.

Em seu início,os associados se reuniam semanalmente para a realização das compras em conjunto,ficando as negociações a cargo do presidente. Esse processo se tornou extremamente desgastante,visto que o presidente também possuía suas próprias lojas para administrar. Com o crescimento da Rede Econômica, a solução encontrada foi a criação de uma Central Administrativa,que pudesse cuidar apenas do gerenciamento da rede,além de ser espaço apropriado para reuniões e trocas de experiência e discussão de novas idéias. 
A Central Administrativa da Rede é independente das lojas associadas e possui autonomia de ação dentro dos limites estabelecidos pelo estatuto e regimento interno. As princi pais funções desempenhadas pela administração da Rede Econômica são: compras e abastecimento,gestão administrativa e financeira, marketing e treinamento.

\subsection{APLICAÇÃO DA TIPOLOGIA}

Após a descrição e caracterização da Rede Econômica de Supermercados, a análise dessa rede foi feita por meio da aplicação da tipologia proposta por Hoffmann etal. (2004). Como já explicado no referencial teórico,essa ti pologia é composta por quatro indicadores: direcionalidade, localização,formalização e poder.

\subsubsection{DIRECIONALIDADE}

Com relação ao aspecto da direcionalidade, as redes podem ser verticais e horizontais. No caso da rede em estudo,esta pode ser considerada do tipo horizontal,pois em rede horizontal as relações de cooperação ocorrem entre empresas que possuem produtos similares e pertencem a um mesmo setor de atuação.

Vale destacar que,na Rede Econômica de Supermercados, as relações de cooperação se dão entre empresas do mesmo setor,isto é,o setor de comércio varejista. Além disso,as empresas que pertencem à rede são do mesmo porte, mais especificadamente enquadradas como micro e pequenas empresas. $\mathrm{O}$ fato de a associação não possuir empresas de grande porte impede o aparecimento de hierarquia na rede,que é aspecto de redes verticais,não de horizontais.

A rede em estudo também pode ser considerada horizontal pelo fato de que os objetivos são definidos para o alcance de metas que não poderiam ser atingidos de maneira individual. Esses mesmos objetivos são determinados de forma democrática,de acordo com os interesses da maioria.

\subsubsection{LOCALIZAÇÃO}

No que se refere à localização,as redes podem ser dispersas ou aglomeradas. A Rede Econômica pode ser considerada rede que possui estrutura territorialmente aglomerada. Das dezoito lojas pertencentes à associação,dezesseis delas se encontram espalhadas pela cidade de Limeira. Já as duas lojas que completam a rede se encontram uma em Iracemápolis e a outra em Santa Bárbara d'Oeste, cidades muito próximas a Limeira. 
É importante destacar,mais uma vez,que as empresas da Rede estão estrategicamente distantes umas das outras,com o objetivo de evitar a concorrência direta. Questionado sobre os planos de expansão da Rede Econômica,o gestor afirma que,tendo em vista o objetivo de se evitar a concorrência direta pela proximidade geográfica,a única solução é a busca de parceiros nas cidades vizinhas. Tal postura explica a partici pação na Rede de lojas fora da cidade de Limeira.

Segundo o gestor da rede, existem contatos sendo realizados com outras lojas em cidades na região,como Rio Claro e Araras,para que estas possam integrar-se à associação. Com isso,à medida que a Rede vá crescendo,a tendência é que ocorram mudanças no sentido de que a aglomeração das empresas caminhe do nível local para o regional.

\subsubsection{FORMALIZAÇÃO}

Quanto à formalização,as redes podem ter estruturas formais,com base em contratos ou outros instrumentos legais, ou podem ser informais,sem base contratual. A Rede Econômica de Supermercados possui estrutura formal,visto que a partici pação dos supermercados na associação se dá por meio de assinatura de contrato de adesão.

A Rede Econômica possui estatuto e regimento interno,em que estão contidos os deveres e as obrigações dos associados, além das normas que regem a associação em si. Nesses instrumentos também estão previstas as sanções,como aplicação de multas,aos membros que eventualmente venham a descumprir o que foi formalmente estabelecido. Contudo,segundo o gestor, não existe, por parte dos associados,o descumprimento de normas e regulamentos. O estatuto e o regimento interno foram definidos por ocasião da fundação da Associação, não tendo sofrido grandes alterações até o momento.

Além de ditar as normas de atuação dos associados,o estatuto e o regimento interno tratam da forma de ação da Central Administrativa da Rede. Todas as despesas realizadas pela administração,como gastos com funcionários,equi pamentos, veículos, entre outras, são pagas pelos associados, após a divisão dos valores entre as dezoito lojas da Rede.

\subsubsection{PODER}

No que se refere ao aspecto poder,ligado à capacidade de decisão,as redes podem ser orbitais ou não-orbitais. As redes orbitais se caracterizam por ter hierarquia de poder: uma empresa tem maior poder de decisão que as outras. Já nas não-orbitais,todos os partici pantes têm o mesmo poder de decisão. 
A Rede Econômica de Supermercados é claramente um exemplo de rede não-orbital,e isso pode ser comprovado pela estrutura definida pela Rede para a tomada de decisões. A Associação possui um presidente,que é um dos proprietários de lojas,com mandato de um ano. Os próximos nomes para a presidência já estão previamente definidos por escala elaborada de comum acordo entre todos os membros.

Semanalmente,os proprietários das lojas se reúnem para a tomada de decisões estratégicas e definições dos objetivos da Rede. Todos os proprietários têm o mesmo poder de decisão,mesmo existindo membros possuidores de mais de uma loja. Existem apenas treze votos no processo de tomada de decisão,incluindo o voto de Minerva do presidente. As decisões referentes às promoções são tomadas pelo gestor da Rede juntamente com alguns membros previamente escolhidos. Existem quatro grupos de proprietários que se revezam semanalmente para a definição das promoções a serem realizadas. As demais decisões operacionais são tomadas pela Central de Administração.

\subsection{VANTAGENS PROPORCIONADAS PELA REDE}

Muitas vantagens são obtidas pelas empresas ao trabalharem na forma de rede. Uma delas,que foi um dos fatores que levaram à criação da Rede,é a possibilidade da realização de compras em conjunto,que permite negociação direta com as indústrias e a obtenção de menores preços,em virtude do maior volume adquirido.

Para o gerente de compras,além da possibilidade de compra em conjunto, a grande vantagem para os micro e pequenos proprietários é a realização do marketing conjunto. Ele explica a razão dessa vantagem,dizendo que "a realização de ações de marketing de maneira individual seria muito dispendiosa,em virtude dos altos custos, e, portanto, inviável para pequenos supermercados". Essa questão do marketing se mostra muito forte na Rede,visto que esta realiza ações de marketing promocional,sazonal,social e institucional.

O marketing promocional é utilizado para divulgar os dias em que produtos específicos se encontram com preços especiais em todas as lojas da Rede Econômica. É importante ressaltar que as lojas têm o compromisso de manter os mesmos preços apenas nos produtos em promoção,ficando os preços de outros produtos a critério de cada loja. A divulgação é feita por meio de panfletos,tablóides,banners e camisetas. O marketing sazonal se refere às promoções realizadas por ocasião de datas comemorativas,como o aniversário da Rede Econômica,por exemplo. O marketing social se concentra em ações de apoio a campanhas sociais realizadas na cidade,como a Campanha do Agasalho. 
As ações da Rede Econômica com relação ao marketing institucional se concentram na padronização das lojas,na aquisição de veículos estilizados,no uso de uniformes padronizados, além da criação de um cartão da Rede,que possibilita aos clientes a realização de compras para pagamento a prazo. A Rede Econômica,por meio de sua administração,promove cursos e treinamentos para os lojistas e seus funcionários. Todas essas ações visam ao fortalecimento da Rede ante os consumidores, passando a estes a imagem de estabelecimentos de qualidade e credibilidade.

Outro fator que possibilita a melhoria da imagem da Rede perante os clientes é a venda de produtos com a marca da Rede Econômica de Supermercados, porque a venda de produtos de marca própria só é possível,na maioria das vezes, a grandes redes de supermercados. Os produtos comercializados com a marca da Rede Econômica são: macarrão,arroz,feijão,café,achocolatado em pó e refrigerantes.

De modo geral,a partici pação dos micro e pequenos supermercados na Rede têm possibilitado a estes a sobrevivência em mercado cada vez mais competitivo. Além disso,as lojas da rede tiveram,segundo o gestor da Rede Econômica,um aumento de $35 \%$ no faturamento individual. Nas palavras dele,"existem muitos proprietários que estão bem,investindo nas lojas e até mesmo adquirindo propriedades,carros e outros bens".

\subsection{DIFICULDADES PERCEBIDAS DENTRO DA REDE}

A principal dificuldade encontrada dentro da Rede Econômica se concentra nos problemas existentes na conciliação dos interesses coletivos com os interesses individuais. Segundo o gestor,esses conflitos não são freqüentes,mas existem,princi palmente quando os associados tentam impor preferências pessoais nas decisões da Rede.

Para o gestor, "onde existem muitas pessoas sempre vão existir os conflitos, pois cada um defende sempre seu lado". Contudo,esses conflitos de interesses são administrados de forma democrática,já que todas as decisões são tomadas por meio de votação entre os associados,em que a maioria simples vence.

\section{CONCLUSÕES}

O objetivo principal deste artigo foi realizar uma análise do caso da Rede Econômica de Supermercados, classificando-a de acordo com a tipologia proposta por Hoffmann etal. (2004), e identificar as vantagens da associação,bem como as dificuldades no funcionamento da Rede. Com base nas informações 
obtidas nas entrevistas e na análise dos documentos conseguidos,algumas considerações podem ser feitas sobre essa Rede.

A Rede Econômica de Supermercados é associação que reúne micro e pequenos supermercados e, de acordo com a ti pologia utilizada nesse estudo,pode ser classificada como de cooperação horizontal,aglomerada,formal e não-orbital.

Além da possibilidade de realização de compras em conjunto,o que proporciona um poder de negociação maior com os fornecedores,a princi pal vantagem que foi percebida no estudo está ligada à questão do marketing. Em razão do porte das empresas,a realização de ações de marketing só está sendo possível pela união por intermédio da rede. As ações de marketing dos ti pos promocional, sazonal,social e institucional têm contribuído para a melhoria da imagem da Rede como um todo e para o aumento da lucratividade dos supermercados. O princi pal problema percebido foi a dificuldade de conciliar os interesses coletivos com os interesses individuais,o que foi superado pela tomada democrática de decisões.

Os resultados obtidos com base na análise do caso permitem que sejam feitas a lgumas considerações finais. As características apresentadas pela Rede Econômica,por exemplo, estão de acordo com as características de redes de PME apresentadas por Balestrin e Vargas (2003). Além disso,como já verificado por Pereira (2004) e Tondolo e Schneider (2004),um dos princi pais benefícios proporcionados pela associação dos supermercados na Rede Econômica se concentra nas ações da área de marketing. Como observa Balestro (2004),um dos fatores centrais para o funcionamento de uma rede de empresas é a existência de uma central de coordenação,o que foi comprovado pelo depoimento do gestor administrativo da Rede Econômica. Enfim,o estudo de caso da Rede Econômica vai ao encontro do que já se tem relatado na literatura sobre redes de PME,corroborando e comprovando estudos anteriores já realizados.

\section{REFERÊNCIAS}

AMATO NETO,J. Redes de cooperação produtiva e clusters regionais. São Paulo: Atlas,200o. BALESTRIN,A.; VARGAS,L. M. Redes horizontais de cooperação como estrutura favorável para o desenvolvimento das PMEs. In: ENCONTRO DA ASSOCIAÇÃO NACIONAL DE PROGRAMAS DE PÓS-GRADUAÇÃO EM ADMINISTRAÇÃO,27,2003,Atibaia. Anais... Atibaia: Anpad,2003.

A dimensão estratégica das redes horizontais de PMEs: teorizações e evidências. Revista de Administração Contemporânea,v. 8,p. 203-227,2004. Edição especial

BALESTRO,M. V. Características estruturais e mecanismos de governança: apontamentos conceituais. In: VERSCHOORE,J. R. (Org.). Redes de cooperação: uma nova organização de pequenas e médias empresas no Rio Grande do Sul. Porto Alegre: FEE,2004. 
BALESTRO,M. V. etal. A experiência da Rede Petro-RS: uma estratégia para o desenvolvimento das capacidades dinâmicas. Revista de Administração Contemporânea,v. 8,p. I8I-202,2003. Edição especial.

CARRÃO,A. M. R. Cooperação entre empresas de pequeno porte. Revista de Administração da USP,v. 39,n. 2,p. I85-186,abr./jun. 2004.

CARSTENS,D. D. S.; TEIXEIRA,R. M. Redes interorganizacionais de PMEs: fatores de cooperação e aprendizado. In: ENCONTRO DE ESTUDOS SOBRE EMPREENDEDORISMO E GESTÃO DE PEQUENAS EMPRESAS,3,2003,Curitiba. Anais... Curitiba: Egepe,2005.

CASSAROTO FILHO,N.; PIRES,L. H. Redes de pequenas e médias empresas e o desenvolvimento local. São Paulo: Atlas,I998.

DOZ,Y. L. The evolution of cooperation in strategic alliances: initial conditions or learning processes. Strategic Management Journal,v. I7,p. 55-83,I996.

EBERS,M.; JARILLO,J. C. The construction,forms and consequences of industry networks. International Studies of Management \& Organization,v. 27,n. 4,p. 3-2I,I997.

FARIAS FILHO,J. R.; CASTANHA,A. L. B.; PORTO,C. B. Arquiteturas em redes: um novo paradigma competitivo para as micro,pequenas e médias empresas. In: ENCONTRO DA ASSOCIAÇÃO NACIONAL DE PROGRAMAS DE PÓS-GRADUAÇÃO EM ADMINISTRAÇÃO,23,I999, Foz do Iguaçu. Anais... Foz do Iguaçu: Anpad,I999.

FULLER-LOVE,N.; THOMAS,E. Networks in small manufacturing firms. Journal of Small Business Development,v. II,n. 2,p. 244-253,2004.

GRANDORI,A.; SODA,G. Inter-firm networks: antecedents,mechanisms and forms. Organizations Studies,v. I6,n. 2,p. I83-214,I995.

GIL,A. C. Métodos e técnicas de pesquisa social. 5. ed. São Paulo: Atlas,I999.

HOFFMANN,V. E.; MOLINA-MORALES, F. X.; MARTÍNEZ-FERNANDEZ, M. T. Redes de empresas: uma ti pologia para sua classificação. In: ENCONTRO DA ASSOCIAÇÃO NACIONAL DE PROGRAMAS DE PÓS-GRADUAÇÃO EM ADMINISTRAÇÃO,28,2004,Curitiba. Anais... Curitiba: Anpad,2004.

JARILLO,J. C. On strategic networks. Strategic Management Journal,v. 9,p. 3I-4I,I988.

LANIADO,R. N.; BAIARDI,A. A contribuição das redes na formação da cooperação empresarial -um estudo de caso. Organizações \& Sociedade,v. Io,n. 27,p. 6I-74,mai./ago. 2003.

PEREIRA,R. C. F. Marketing em redes de cooperação: um estudo de caso em uma rede varejista. In: ENCONTRO NACIONAL DE ESTUDOS ORGANIZACIONAIS,3,2004,Atibaia. Anais... Atibaia: Anpad,2004.

SEBRAE. Enquadramento das MPES. Disponível em: <www.sebrae.gov.br/parasuaempresa/ enquadramentompes.asp>. Acesso em: 20 set. 2005.

TONDOLO,V. A. G.; SCHNEIDER, L. C. Vantagens logísticas na cadeia de valor na rede de empresas: o caso de uma rede gaúcha de pequenas farmácias. In: ENCONTRO DA ASSOCIAÇÃO NACIONAL DE PROGRAMAS DE PÓS-GRADUAÇÃO EM ADMINISTRAÇÃO,28,2004,Curitiba. Anais... Curitiba: Anpad,2004.

TROCCOLI,I. R.; MACEDO-SOARES,T. D. L. A. Gestão de empresas em grupos estratégicos. Revista de Administração da USP,v. 38,n. 3,p. I8I-I9I,jul./set. 2003.

VERGARA,S. C. Projetos e relatórios de pesquisa emadministração. São Paulo: Atlas,I998. 
YIN,R. K. Estudo de caso: planejamento e métodos. 2. ed. Porto Alegre: Bookman,200I.

WILDER,A. Mudanças no setor supermercadista e a formação de pequenos supermercados. 2003. Dissertação (Mestrado) - Escola Superior de Agricultura "Luiz de Queiroz", Universidade de São Paulo,Piracicaba,2003.

WITTMANN,M. L.; NEGRINI,F.; VENTURINI,T. As redes empresariais como alternativa para aumentar a competitividade de empresas do setor varejista. In: ENCONTRO DE ESTUDOS EM ESTRATÉGIA,3,2003,Curitiba. Anais... Curitiba: Anpad,2003.

\section{TRAMITAÇÃO}

Recebido em 29/8/2006

Aprovado em30/12/2006 